\title{
Obtaining Consent from Both Parents for Pediatric Research: What Does "Reasonably Available" Mean?
}

AUTHORS: Daniel K. Nelson, MS,a,b Debra Skinner, PhD, b,c Sonia Guarda, MS, ${ }^{\text {b,c }}$ Summer Choudhury, MA, ${ }^{d}$ John

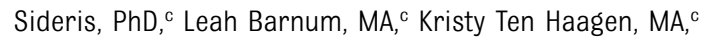
Quetrell Heyward, BS, ${ }^{\mathrm{c}}$ and Donald B. Bailey Jr, PhD ${ }^{\mathrm{b}, \mathrm{e}}$

aDepartments of Social Medicine and Pediatrics, ${ }^{b}$ Center for Genomics and Society, ${ }^{\circ} F P G$ Child Development Institute, and dDivision of Pulmonary and Critical Care Medicine, University of North Carolina at Chapel Hill, Chapel Hill, North Carolina; and e RTI International, Research Triangle Park, North Carolina

\section{KEY WORDS}

informed consent, parental consent, IRB regulations, pediatric research, newborn screening

\section{ABBREVIATIONS \\ FDA—Food and Drug Administration \\ $F X$ - fragile $X$ \\ IRB-institutional review board \\ NBS—newborn screening \\ RA-research assistant \\ UNC_-University of North Carolina}

Mr Nelson made substantial contributions to the conception and design, analysis, and interpretation of data and drafted the article for intellectual content. Dr Skinner made substantial contributions to the conception and design; acquisition, analysis, and interpretation of data; and helped draft the article for intellectual content. Ms Guarda and Choudhury made substantial contributions to the acquisition, analysis, and interpretation of data and helped draft the article for intellectual content. Dr Sideris made substantial contributions to analysis and interpretation of data and helped draft article for intellectual content. Ms Barnum made substantial contributions to the analysis of data and helped revise the article for intellectual content. Ms Ten Haagen made substantial contributions to the acquisition, analysis, and interpretation of data and helped revise the article for intellectual content. $\mathrm{Mr}$ Heyward made substantial contributions to the analysis and interpretation of data and helped draft the article for intellectual content. Dr Bailey made substantial contributions to the conception and design, analysis, and interpretation of data and helped draft the article for intellectual content. All authors read and approved the manuscript submitted.

www.pediatrics.org/cgi/doi/10.1542/peds.2012-1278

doi:10.1542/peds.2012-1278

Accepted for publication Sep 17, 2012

Address correspondence to Daniel K. Nelson, MS, Office of Human Research Ethics, University of North Carolina at Chapel Hill, CB \#7097, Chapel Hill, NC 27599-7097. E-mail: daniel_nelson@unc.edu PEDIATRICS (ISSN Numbers: Print, 0031-4005; Online, 1098-4275). Copyright (c) 2013 by the American Academy of Pediatrics

(Continued on last page)
WHAT'S KNOWN ON THIS SUBJECT: When research involving children is determined to present greater than minimal risk but no potential for direct benefit, permission is required from both parents, unless one is not reasonably available. These requirements are variably understood and applied, and guidance is lacking.

WHAT THIS STUDY ADDS: In a study on newborn screening, a sizeable percentage of fathers were not reasonably available, reflecting complexities of parental status and family relations. Guidelines developed in this project may provide tools for researchers and institutions to apply in other contexts.
OBJECTIVE: Circumstances surrounding parental availability and decision-making were examined in the setting of a research protocol involving newborn screening (NBS) for fragile $X$ syndrome, in which the institutional review board (IRB) had determined that consent (permission) was required from both parents.

METHODS: A survey was conducted with 3001 families who were approached to participate in optional NBS. In addition to basic demographics, observational notes detailed the reasons why fathers were not present or deemed "not reasonably available" (per IRB regulations), and content analysis identified the factors for this lack of availability. Logistic regression models estimated the likelihood that both parents would agree to enroll their infant in the screening project.

RESULTS: Fathers were not present in 589 cases, including 158 in which fathers were ultimately determined to be not reasonably available. Primary reasons for father's unavailability were deployment with the military, incarceration, living out of state, or not involved in the mother's life. In cases in which both parents were available, 64\% agreed to enroll in the NBS study. Criteria to guide researchers in making required determinations were developed from consultations with IRB officials and legal counsel.

CONCLUSIONS: In a large-scale population-based study, $19.6 \%$ of fathers were absent for the consent process. Scenarios encountered underscore the complexity of parental relations and their implications for obtaining consent for research involving children. The algorithm developed may serve as a useful tool for others in applying the regulatory requirements for dual parental permission. Pediatrics 2013;131:e223-e229 
Obtaining legally effective informed consent before participation is one of the fundamental protections for human research subjects. When research involves children, permission from 1 or both parents is generally required, depending on study circumstances. Federal regulations for research involving children (Subpart D, 45 CFR 46.401-409 [US Department of Health and Human Services] ${ }^{1}$ and 21 CFR 50.50-56 [Food and Drug Administration (FDA)] $)^{2}$ categorize protections in terms of the relative balance between risks and benefits and charge institutional review boards (IRBs) with determining that provisions for soliciting parental permission are made accordingly. This regulatory framework has been in effect since 1983 for federally funded research and was extended to FDA-regulated clinical studies in 2001 via congressional mandate. ${ }^{3}$ As such, the vast majority of pediatric research in this country is subject to the Subpart D provisions. These same regulations apply to many international studies when US funding is involved, even if the host country's rules or local IRBs do not require them.

Under these regulations, IRBs may determine that permission from 1 parent is sufficient for research presenting no more than minimal risk $(\S 46.404 / \S 50.5)$ or for studies with greater than minimal risk but with potential for direct benefit to participants $(\S 46.405 / \S 50.52)$. For other categories of research permissible under Subpart D ( $\$ 46.406 /$ $\S 50.53$ or $\S 46.407 / \S 50.54)$ ), "both parents must give their permission unless one parent is deceased, unknown, incompetent, or not reasonably available, or when only one parent has legal responsibility for the care and custody of the child" ( $\$ 46.408 / \S 50.55)$. Beyond that single sentence, there is little to guide investigators, IRBs, or institutional legal counsel in applying these requirements. Even national commissions and advisory committees that examined consent provisions in depth have declined to elaborate on this aspect. ${ }^{3-7}$ In particular, what "reasonably available" should mean is subject to considerable interpretation. In the absence of guidance or consensus, IRBs and investigators have been left to operationalize requirements for dual parental permission in variable and inconsistent ways.

We are aware of no data describing how these requirements are implemented, including how parental availability is determined. We explored this issue in a research project on newborn screening (NBS) for fragile X (FX), in which the IRB required that permission be obtained from both parents. We previously reported rates of parental consent and reasons for accepting or declining screening. ${ }^{8}$ Here we present data related to fathers' availability and role in the decision-making process.

\section{METHODS}

\section{NBS Study}

In February 2009, investigators initiated the Fragile X Newborn Screening Study at the University of North Carolina (UNC) Hospitals, using an experimental screening test that identifies both the FX premutation and full mutation in male and female infants. ${ }^{9} \mathrm{FX}$ syndrome, the most common inherited cause of intellectual disability, is a single gene disorder caused by mutation of the FMR1 gene on the $X$ chromosome. Approximately 1 in 4000 males and 1 in 6000 females are estimated to have the full mutation, and as many as 1 in 290 males and 1 in 129 females may carry the premutation. ${ }^{10,11} \mathrm{FX}$ does not meet current criteria for inclusion in state NBS, primarily because there is no medical treatment or cost-effective test. Moreover, there is concern about identifying carrier children. The rationale for conducting the study is described elsewhere8,12 but centers on the need for empirical research to determine if concerns about risks and benefits of screening for disorders like $F X$ are warranted. The study examines parents' willingness to accept screening for a condition that is not medically treatable or that could identify newborns as carriers and to examine family adaptation to a positive diagnosis.

\section{IRB Review}

The FX NBS study underwent full board review by the UNC Biomedical IRB, where it generated considerable discussion. The IRB's concerns centered on potential harms from knowledge that the child had an untreatable condition or was a carrier and therefore at risk for late-onset conditions. These concerns reflect current debates over what conditions should be included in NBS. ${ }^{12,13}$ The IRB eventually approved the study under 45 CFR 46.406 as research involving a minor increase over minimal risk and no prospect of direct benefit but likely to yield generalizable knowledge about FX and NBS. As a result, permission was required from both parents. The researchers appealed this decision and met in person with the IRB to argue that the research was not greater than minimal risk. Their own previous work had shown that parents of children with FXS overwhelmingly supported NBS for both carrier and full mutation status ${ }^{14}$ and that notions of benefit were expanding to include benefits to families of learning reproductive risks..$^{15}$ IRB members were divided in their opinions, but ultimately the original finding was upheld. Although the IRB's determination added burden in terms of additional cost and time related to the consent process, it also afforded an opportunity to examine what dual parental permission entails.

\section{Consent and Screening}

Parents were approached on the hospital postpartum unit within 24 hours after birth by a research assistant (RA). 
The RA introduced the study and provided a brochure and consent form describing study aims and procedures, the experimental screening test, information about FX, and risks and benefits of participation. Parents were informed that an extra blood spot would be obtained at the same time as routine NBS, with no additional heel stick. Screening tests were performed in a Clinical Laboratory Improvement Amendments-approved laboratory, and families received notice of results within 4 to 8 weeks. Parents typically had several hours to consider the study before deciding, and an RA was available to answer questions. All materials were available in Spanish, and Spanishspeaking families were approached by a bilingual RA.

\section{Family Scenarios and Consultation}

Early in the study, various scenarios raised questions regarding how to determine whether a father was reasonably available. Because there was no guidance on this issue, study investigators consulted with UNC officials (including the Office of Human Research Ethics, the Office of University Counsel, and the Research Compliance Office) by using actual and hypothetical situations.

The first set of questions related to the legal rights of the father to consent, even if he was a minor, not married to the mother, or not on good terms with her. The consensus was that a father's rights depend heavily on whether he is listed on the birth certificate. In North Carolina, the father's name is automatically written on the birth certificate if he is married to the mother. He does not need to be present, and no proof has to be provided. However, the mother can choose not to put him on the birth certificate. If the parents are not married, both must be present and provide a valid government-issued picture ID. In these circumstances, both must sign an affidavit of paternity before the father's name is written on the birth certificate. If the father was on the birth certificate, regardless of marital status, age, or nature of his relationship with the mother, the consensus opinion was that his permission must be sought unless he was not reasonably available or legal proceedings had terminated his parental rights. If he was not on the birth certificate, the consensus was that there was less responsibility to obtain his permission; however, if he was involved and available, his permission should still be sought. If this involved/available father then declined screening, we were advised to omit the child from the study.

Once we established these criteria for fathers whose permission should be sought, the next challenge was to determine if fathers were reasonably available. Scenarios included a mother who agreed to the study but indicated the father was not involved. He was on the birth certificate but did not live with the mother. The mother provided his phone number. Counsel's advice was that we should attempt to obtain father's consent because he was on the birth certificate and was reasonably available, at least by phone. In another scenario, the mother gave permission, but her husband was not in the state, and she would not provide contact information. Counsel considered this father to be not reasonably available.

Unusual scenarios included a mother's legal spouse who was not the biological father but was named on the birth certificate. We were counseled that permission from the biological father was not required unless paternity had been established by court order. In this case, information on the birth certificate effectively trumped whatever the research team might have known about the family situation. In another case, the mother was married but was going to do a paternity test to determine the father before putting him on the birth certificate. Here, we considered the mother's permission to be sufficient. For same-sex couples, the consensus was that permission from the partner was not legally required unless she was designated as a parent/ guardian but that the birth mother's wishes should dictate.

On the basis of these consultations, we established procedures for determining father availability, outlined in Fig 1. Once eligible mothers agreed to participate, RAs determined if absent fathers were involved and/or listed on the birth certificate. (If the mother declined participation and the father was absent, RAs did not pursue information about him.) RAs then asked if the father would be coming to the hospital. If so, he was considered potentially available. If not, the RA asked if he was "involved" with the mother/family. If involved but at work or otherwise in the area, the mother was given a prepaid envelope with a study brochure and consent form for the father to sign and return, if he agreed. If involved but not easily contacted, we considered the father to be not reasonably available. If the mother said the father was "not involved," the RA asked if he was on the birth certificate. If not, his permission was not pursued. If he was, then his consent was required unless he was not reasonably available. In a few instances, the father was on the birth certificate but not involved. These were delicate situations that RAs explored diplomatically to determine if the father should be considered "available." Usually in these cases, the mother did not want us to contact the father and was unwilling to provide contact information, making him not reasonably available.

After parents made their decisions, RAs conducted a brief survey related to their decisions and collected basic demographic data on both parents when possible. RAs also made notes about 


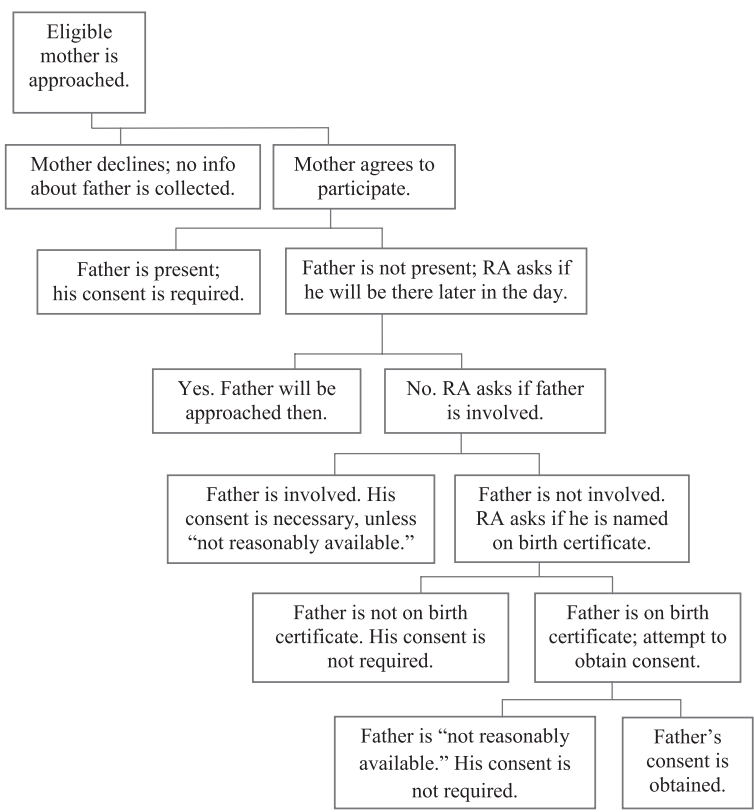

FIGURE 1

Algorithm for determining father's availability to give consent.

scenarios encountered, including reasons for father's unavailability.

\section{Data Analysis}

Descriptive analyses were conducted on parents who consented to or declined screening or who were not available, and on the degree of consensus among couples. Education, marital status, race/ethnicity, number of live births for mother, and mother's age were used in logistic regression models to predict agreement to screening. Models were estimated by using SAS (SAS Institute Inc, Cary, NC) "proc genmod," which allows for the estimation of between group differences in likelihood and tests of those estimates. Following standard procedures for content analysis, ${ }^{16,17} 2$ of the authors independently coded RA notes to determine the different scenarios comprising father unavailability. Discrepancies in coding were few in number and were reconciled by the second author.

\section{RESULTS}

From February 2009 through October 2010, RAs approached 3106 families. Of these, 3001 (97\%) were willing to hear about FX NBS. Table 1 provides demographic information on parents who filled out the brief survey. Table 2 provides rates across all mothers and all fathers, irrespective of their partner's decision. Table 3 provides information on agreement/disagreement rates among paired couples. Similar to our previous findings, $868 \%$ of mothers agreed to have their newborns screened, but the overall acceptance rate dropped slightly to $64 \%$ (Table 3). The father's status was considered "not applicable" when he was not present and the mother declined screening $(n=327)$, at which point his availability was not determined and his permission was not pursued. For 262 fathers, it was necessary to determine availability. Of these, the father was considered "not available" when the mother gave permission but he was not reasonably available $(n=158)$. In the remaining 104 cases, the father was absent but determined to be reasonably available, and a consent form was sent home with the mother (31 fathers returned a signed form, 73 did not).

Removing fathers who were either not applicable or not available $(n=485)$, acceptance rates of fathers as compared with mothers were similar, with $71 \%$ of fathers and $68 \%$ of mothers agreeing to FX NBS (Table 2). Most couples (79\%) agreed with each other, either to accept or decline screening. Five percent disagreed (Table 3). These cases of parental disagreement were not contentious and generally involved 1 parent wanting to know the genetic status of their newborn but the other did not.

To examine if agreement varied by demographic characteristics, we ran 2 logistic regression models, 1 predicting the mother's likelihood to accept screening (Table 4) and the other predicting the father's likelihood (Table 5). In the model of mother agreement, we used mother's race, marital status, education, age, and number of live births. In the fathers' model, we used the same variables with the exception of age. For mothers (Table 4), there were some effects of race/ethnicity. African American respondents were half as likely to accept screening, compared with either Hispanic (odds ratio $=0.55$ ) or white (odds ratio $=$ 0.52 ) respondents. Those classified as "Other" were approximately one-third as likely to agree as white respondents. In general, education was positively correlated to willingness to participate in screening. However, only 2 comparisons were significant: between education of less than high school and either BA or graduate degree. Maternal age was also a significant predictor, although the effect was comparatively small, with a slight decrease in agreement between mothers and fathers as mothers got older. For fathers as with mothers, there was a significant effect for race, with African Americans $\sim 60 \%$ as likely to agree to screening as whites.

In total, 589 (19.6\%) of fathers were not present for the initial consent process for a variety of reasons. We went on to determine the father's availability in 
TABLE 1 Demographic Features of Families

\begin{tabular}{|c|c|c|}
\hline \multirow[t]{2}{*}{ Feature } & \multirow{2}{*}{$\frac{\text { Mother }}{(n=3001)}$} & \multirow{2}{*}{$\begin{array}{c}\text { Father } \\
(n=1990)\end{array}$} \\
\hline & & \\
\hline Mean age, y & 28 & Not collected \\
\hline Marital status, $\%$ & & Not collected \\
\hline $\begin{array}{l}\text { Single, never } \\
\text { married }\end{array}$ & 38.0 & \\
\hline Married & 59.4 & \\
\hline Previously married & 2.6 & \\
\hline \multicolumn{3}{|l|}{ Education, \% } \\
\hline$<$ High school & 29.6 & 29.5 \\
\hline High school degree & 15.7 & 18.1 \\
\hline Some college & 17.3 & 15.0 \\
\hline College degree & 17.3 & 16.3 \\
\hline Graduate degree & 20.7 & 21.1 \\
\hline \multicolumn{3}{|l|}{ Race/ethnicity, \% } \\
\hline African American & 13.7 & 14.0 \\
\hline Latino/Hispanic & 37.6 & 36.9 \\
\hline White & 40.8 & 41.9 \\
\hline Other & 7.9 & 7.1 \\
\hline \multicolumn{3}{|l|}{ Language, \% } \\
\hline English & 62.3 & 62.9 \\
\hline Spanish & 33.3 & 32.8 \\
\hline Other & 4.3 & 4.7 \\
\hline \multicolumn{3}{|l|}{ Gender of newborn, \% } \\
\hline Male & 50.7 & \\
\hline Female & 49.3 & \\
\hline $\begin{array}{l}\text { Number of live births, } \\
\text { including newborn, \% }\end{array}$ & & Not collected \\
\hline 1 & 37.9 & \\
\hline 2 & 33.4 & \\
\hline 3 & 17.6 & \\
\hline 4 & 7.0 & \\
\hline$>5$ & 4.0 & \\
\hline
\end{tabular}

262 cases. The algorithm for operationalizing the process to determine availability (Fig 1) included consideration of (1) the relative involvement of the father, (2) whether the father was on the birth certificate, and (3) difficulty of contact. Content analysis indicated 4 primary and sometimes overlapping reasons for unavailability of fathers who were (1)

TABLE 2 Decisions by Mothers and Fathers as a Group, Without Respect to Their Paired Partners

\begin{tabular}{lcccc}
\hline & Frequency $\%$ & $\begin{array}{c}\text { Cumulative } \\
\text { Frequency }\end{array}$ & $\begin{array}{c}\text { Cumulative } \\
\%\end{array}$ \\
\hline \multicolumn{5}{c}{ Mother agrees to participate } \\
No & 950 & 31.66 & 950 & 31.66 \\
Yes & 2051 & 68.34 & 3001 & 100.00 \\
No & 738 & 24.59 & 738 \\
Yes & 1778 & 59.25 & 2516 & 24.59 \\
N/A & 485 & 16.16 & 3001 & 100.00 \\
\hline a See Table 3 for details on fathers who were either "not \\
applicable" or "not available."
\end{tabular}

uninvolved in the mother's life, (2) out of state, (3) on military deployment, or (4) incarcerated.

\section{DISCUSSION}

For nearly 3 decades, regulatory provisions under Subpart $D^{1}$ have governed federally supported research with children, and Congress mandated adoption by the FDA in 2001.2,3 As a result, the consent requirements we

TABLE 3 Consent Outcomes for Mothers and Fathers as Paired Couples

\begin{tabular}{llrr}
\hline Mother & Father & Freq. & $\%$ \\
\hline Yes & Yes & 1760 & 58.7 \\
Yes & No & 133 & 4.4 \\
Yes & NAv & 158 & 5.3 \\
No & Yes & 18 & 0.6 \\
No & No & 605 & 20.2 \\
No & NAp & 327 & 10.9 \\
\hline
\end{tabular}

Freq. frequency: NAp, not applicable: Cases in which father was not present but was not pursued, because mother had already declined; NAv, not available: cases in which mother accepted but father was not reasonably available for consent.

TABLE 4 Relationship Between Selected Maternal Demographic Variables and Acceptance of FX NBS

\begin{tabular}{lccc}
\hline & OR (SE) & $\mathrm{Cl}$ & $\chi^{2}$ \\
\hline Asian versus African American & $1.3(0.32)$ & $0.8-2.11$ & 1.12 \\
Asian versus Hispanic & $0.7(0.17)$ & $0.43-1.14$ & 2.08 \\
Asian versus other & $1.31(0.38)$ & $0.75-2.3$ & 0.89 \\
Asian versus white & $0.61(0.13)$ & $0.4-0.94$ & $5.05^{\mathrm{a}}$ \\
African American versus Hispanic & $0.54(0.08)$ & $0.4-0.73$ & $16.76^{\mathrm{b}}$ \\
African American versus other & $1.01(0.22)$ & $0.65-1.56$ & 0.01 \\
African American versus white & $0.47(0.06)$ & $0.36-0.61$ & $30.3^{\mathrm{b}}$ \\
Hispanic versus other & $1.87(0.41)$ & $1.21-2.87$ & $8.06^{\mathrm{c}}$ \\
Hispanic versus white & $0.87(0.12)$ & $0.67-1.13$ & 1.13 \\
Other versus white & $0.46(0.1)$ & $0.31-0.7$ & $13.72^{\mathrm{b}}$ \\
Single versus married & $1.31(0.14)$ & $1.06-1.62$ & 6.33 \\
Single versus previously married & $0.88(0.26)$ & $0.49-1.57$ & 0.18 \\
Married versus previously married & $0.67(0.2)$ & $0.38-1.19$ & 1.86 \\
Less than HS versus HS degree & $0.76(0.12)$ & $0.56-1.04$ & 3.02 \\
Less than HS versus some college & $0.89(0.16)$ & $0.63-1.26$ & 0.44 \\
Less than HS versus bachelor's degree & $0.54(0.1)$ & $0.37-0.78$ & $10.44^{\mathrm{c}}$ \\
Less than HS versus graduate degree & $0.78(0.12)$ & $0.58-1.05$ & 2.76 \\
HS degree versus some college & $0.91(0.15)$ & $0.65-1.26$ & 0.34 \\
HS degree versus BA/BS & $0.55(0.1)$ & $0.38-0.78$ & $10.93^{\mathrm{b}}$ \\
HS degree versus graduate degree & $1.17(0.18)$ & $0.86-1.58$ & 1.02 \\
Some college versus bachelor's degree & $0.7(0.12)$ & $0.51-0.97$ & $4.48^{\mathrm{a}}$ \\
Some college versus graduate degree & $0.6(0.09)$ & $0.46-0.8$ & $12.61^{\mathrm{b}}$ \\
Bachelor's degree versus graduate degree & $1.3(0.32)$ & $0.8-2.11$ & 1.12 \\
Mother's age & $0.98(0.38)$ & $0.97-0.98$ & $4.65^{\mathrm{a}}$ \\
Number of live births & $0.94(0.08)$ & $0.97-1.16$ & 1.90 \\
\hline Cl, confidence interval; HS, high school; 0R, odds ratio. & & & \\
a $P<.01$. & & & \\
b $P<.0001$. & & & \\
c $P<.001$. & & &
\end{tabular}

examined have been used in thousands of pediatric protocols in this country and abroad. Despite this widespread experience, we are aware of no data describing efforts to solicit permission from both parents, with particular regard to availability. Federal regulations (45 CFR 46.408, 21 CFR 50.55)1,2 hint only that the requirement for dual parental permission is not absolute if 1 of the parents is "not reasonably available." IRBs and investigators routinely struggle with these requirements in the absence of any consensus or benchmarks that would guide their application to individual research projects. ${ }^{3-7}$ Indeed, this was confirmed at 2 other sites conducting similar NBS projects for FX where $1 \mathrm{IRB}$ required both parents' consent and the other did not Although the exceptions for parents who are deceased, unknown, incompetent, or do not have legal responsibility may be easier to apply, the 
TABLE 5 Relationship Between Selected Paternal Demographic Variables and Acceptance of FX NBS

\begin{tabular}{lccc}
\hline & OR (SE) & Cl & $\chi^{2}$ \\
\hline Asian versus African American & $1.05(0.31)$ & $0.59-1.87$ & 0.02 \\
Asian versus Hispanic & $0.78(0.23)$ & $0.44-1.4$ & 0.7 \\
Asian versus other & $0.74(0.28)$ & $0.35-1.57$ & 0.63 \\
Asian versus white & $0.63(0.16)$ & $0.38-1.05$ & 3.12 \\
African American versus Hispanic & $0.75(0.13)$ & $0.53-1.05$ & 2.76 \\
African American versus other & $0.7(0.23)$ & $0.37-1.33$ & 1.18 \\
African American versus white & $0.6(0.1)$ & $0.43-0.84$ & $8.91^{\text {a }}$ \\
Hispanic versus other & $0.94(0.31)$ & $0.5-1.78$ & 0.03 \\
Hispanic versus white & $0.81(0.14)$ & $0.58-1.12$ & 1.62 \\
Other versus white & $0.86(0.26)$ & $0.47-1.56$ & 0.25 \\
Single versus married & $1.17(0.15)$ & $0.91-1.51$ & 1.45 \\
Single versus previously married & $1.08(0.39)$ & $0.54-2.19$ & 0.05 \\
Married versus previously married & $0.93(0.33)$ & $0.46-1.86$ & 0.04 \\
Less than HS versus HS degree & $1.09(0.21)$ & $0.74-1.59$ & 0.18 \\
Less than HS versus some college & $0.96(0.21)$ & $0.64-1.46$ & 0.03 \\
Less than HS versus bachelor's degree & $0.76(0.17)$ & $0.5-1.17$ & 1.55 \\
Less than HS versus graduate degree & $1.1(0.2)$ & $0.78-1.57$ & 0.31 \\
HS degree versus some college & $0.98(0.19)$ & $0.67-1.44$ & 0.01 \\
HS degree versus BA/BS & $0.78(0.15)$ & $0.53-1.14$ & 1.64 \\
HS degree versus grad deg & $0.89(0.16)$ & $0.62-1.28$ & 0.41 \\
Some college versus BA/BS & $0.7(0.13)$ & $0.49-1.01$ & 3.57 \\
Some college versus graduate degree & $0.79(0.14)$ & $0.56-1.11$ & 1.81 \\
BA/BS versus graduate degree & $1.05(0.31)$ & $0.59-1.87$ & 0.02 \\
Number of live births & $1.04(1.05)$ & $0.94-1.14$ & 0.53 \\
\hline
\end{tabular}

$\mathrm{Cl}$, confidence interval; HS, high school; OR, odds ratio.

a $P<.001$

exception for availability is at once the most likely reason for relying on 1 parent only and the least well defined. For example, are parents "unavailable" simply because they were working, or does this criterion demand a more permanent or distant separation from the child? If the parents are divorced and living apart but both could be contacted, to what extent should investigators be obligated to seek permission from both? What about situations in which 1 parent is close at hand but clearly uninvolved in the life of the child and the family? How often do investigators encounter these circumstances? These were the types of questions we sought to address.

Results suggest that parental status and relations present challenges in implementing the requirement for dual parental permission in ways perhaps not anticipated when the regulations were originally drafted. Clearly there are many variations on family structure, which IRBs and investigators must consider in mapping an approach to studies requiring permission from both parents. We consulted with institutional legal counsel and IRB officials, and these consultations contributed to the algorithm presented. Key criteria in determining father availability included his relative involvement, whether he was listed on the birth certificate, and difficulty of contact. Of these, birth certificate information effectively trumped other factors. Our default presumption was that father's permission should be sought if he was named on the birth certificate, regardless of marital status or his relationship with the mother. On the other hand, obligations to seek permission from fathers not on the birth certificate shifted more to a matter of courtesy, guided by parents' relationships and level of engagement. This decision tree served us well in appraising each family situation and operationalizing consent requirements in a stepwise manner, and we offer it for other researchers to use or adapt in conducting their own studies.

In this study, nearly $20 \%$ of fathers were not immediately available when mothers were approached. In cases in which a determination of availability had to be made, $40 \%$ of that subset was considered to be "reasonably available," and their permission was required. These figures could equate to hundreds of cases in large population-based research projects. In a study of guardian availability for children presenting to emergency departments, Holmes et al $^{18}$ found that $45 \%$ of children did not have any parent or guardian present during initial evaluation. These authors concluded that research studies on pediatric trauma could be severely limited in obtaining consent, with resulting enrollment bias.

In previous articles, we have described the challenges to informed consent for NBS for FX, and the reasons parents accept or decline such screening.8,12,14,15 Our previous reports focused on the family as a unit and did not examine the inherent challenge of obtaining permission from both mother and father, as was required in the setting of this research study. Parental consent for NBS is not currently obtained in most states because it is conducted under a public health mandate to identify conditions for which there is direct benefit to the child of early detection. This landscape could change as new technologies expand the conditions that can be identified at birth but for which there are no current standardized treatments. If such conditions are added or emerge as incidental findings, then the line between research and clinical care becomes more blurred, and 1- or 2-parent consent may be required. This study points to the potential challenges with this future scenario.

We recognize that this was necessarily an examination of father availability, given the context (NBS) and the obligate 
presence of the mother. Our results may not extrapolate directly to other research studies in which it is more likely that either parent could be absent. We encourage other researchers to examine the circumstances of parental availability in other contexts of pediatric research beyond NBS for which the focus is not as heavily slanted toward the maternal-child pair. It would also be of interest to examine these scenarios

\section{REFERENCES}

1. Code of Federal Regulations. Title 45, Part 46, Subpart D. US Department of Health and Human Services; revised June 18, 1991

2. Code of Federal Regulations. Title 21, Part 50, Subpart D. US Food and Drug Administration; 2001

3. The Office for Human Research Protections. Protections for children in research. A report to Congress in accord with Section 1003 of PL 106-310, Children's Health Act of 2000. US Department of Health and Human Services; 2001. Available at: http://www. hhs.gov/ohrp/archive/reports/ohrp502.pdf. Accessed November 15, 2012

4. Secretary's Advisory Committee on Human Research Protections. Secretarial communications. Washington, DC: Department of Health and Human Services, Office for Human Research Protections. Available at: www.hhs.gov/ohrp/sachrp/commsec/index.html. Accessed April 10, 2012

5. National Human Research Protections Advisory Committee. Reports/documents. Washington, DC: Department of Health and Human Services, Office for Human Research Protections. Available at: www. hhs.gov/ohrp/archive/nhrpac/doc-report. htm. Accessed April 10, 2012

6. Field MF, Berman RE, eds. The Ethical Conduct of Clinical Research Involving Children. in states where laws that govern paternity and parental rights may differ.

\section{CONCLUSIONS}

Our findings contribute empirical data on the availability of fathers to participate in the informed consent process in the setting of a research study on NBS in which permission from both parents was required. The algorithm developed

Institute of Medicine Report. Washington, DC: The National Academies Press; 2004

7. National Bioethics Advisory Commission. Ethical and policy issues in research involving human participants. Washington, DC: Georgetown University. Available at: http://bioethics.georgetown.edu/nbac/ pubs.html. Accessed April 10, 2012

8. Skinner D, Choudhury S, Sideris J, et al. Parents' decisions to screen newborns for FMR1 gene expansions in a pilot research project. Pediatrics. 2011;127(6). Available at: www.pediatrics.org/cgi/content/full/ 127/6/e1455

9. Tassone F, Pan R, Amiri K, Taylor AK, Hagerman PJ. A rapid polymerase chain reaction-based screening method for identification of all expanded alleles of the fragile X (FMR1) gene in newborn and highrisk populations. J Mol Diagn. 2008;10(1): 43-49

10. Hagerman PJ. The fragile $X$ prevalence paradox. J Med Genet. 2008;45(8):498-499

11. Crawford DC, Acuña JM, Sherman SL. FMR1 and the fragile $X$ syndrome: human genome epidemiology review. Genet Med. 2001;3(5): 359-371

12. Bailey DB Jr, Skinner D, Davis AM, Whitmarsh I, Powell C. Ethical, legal, and social concerns about expanded newborn screening: fragile to support this study may provide a useful tool for others to consider in applying the regulatory requirements for dual parental permission. The scenarios encountered and factors that entered into the determinations of availability underscore the complexity of parental status and relations and their implications for obtaining parents' permission for research involving their children.
$\mathrm{X}$ syndrome as a prototype for emerging issues. Pediatrics. 2008;121(3). Available at: www.pediatrics.org/cgi/content/full/121/3/ e693

13. Calonge N, Green NS, Rinaldo P, et al; Advisory Committee on Heritable Disorders in Newborns and Children. Committee report: method for evaluating conditions nominated for population-based screening of newborns and children. Genet Med. 2010;12 (3):153-159

14. Skinner D, Sparkman KL, Bailey DB Jr. Screening for fragile $X$ syndrome: parent attitudes and perspectives. Genet Med. 2003;5(5):378-384

15. Bailey DB Jr, Beskow LM, Davis AM, Skinner $D$. Changing perspectives on the benefits of newborn screening. Ment Retard Dev Disabil Res Rev. 2006;12(4):270-279

16. Miles MB, Huberman AM. Qualitative Data Analysis. Thousand Oaks, CA: Sage Publications; 1994

17. Patton M. Qualitative Research \& Evaluation Methods. Thousand Oaks, CA: Sage Publications; 2002

18. Holmes JF, Holubkov R, Kuppermann N; Pediatric Emergency Care Applied Research Network. Guardian availability in children evaluated in the emergency department for blunt head trauma. Acad Emerg Med. 2009;16(1):15-20

(Continued from first page)

FINANCIAL DISCLOSURE: The authors have indicated they have no financial relationships relevant to this article to disclose.

FUNDING: The Fragile X Newborn Screening Study is supported by the Eunice Kennedy Shriver National Institute for Child Health and Human Development (grant P30 HD003110-S1); the National Human Genome Research Institute's Ethical, Legal, and Social Implications Research Program (grant 5P50HG004488); Centers for Disease Control and Prevention in conjunction with the Association for Prevention Teaching and Research (Cooperative Agreement No. U50/CCU300860, Project TS1470); the National Newborn Screening and Genetics Resource Center, a cooperative agreement between the Maternal and Child Health Bureau, Genetic Services Branch, and the Department of Pediatrics, University of Texas Health Science Center at San Antonio; Health Resources and Services Administration (grant U32MC00148); and the National Center of Research Resources, National Institutes of Health (grant UL1RR02574). Funded by the National Institutes of Health (NIH). 